\title{
A STUDY ON MHD BOUNDARY LAYER FLOW OVER A NONLINEAR STRETCHING SHEET USING IMPLICIT FINITE DIFFERENCE METHOD
}

\author{
Satish V Desale ${ }^{1}$, V H Pradhan ${ }^{2}$ \\ ${ }^{I}$ R.C.Patel Institute of Technology, Shirpur, India satishdesale@gmail.com \\ ${ }^{2}$ S.V.National Institute of Technology, Surat, India pradhan65@yahoo.com
}

\begin{abstract}
The problem of the MHD boundary layer flow of an incompressible viscous fluid over a non-linear stretching sheet is discussed. Using similarity transformation governing equations are transformed in to nonlinear ordinary differential equation. The Implicit finite difference Keller box method is applied to find the numerical solution of nonlinear differential equation. Graphical results of fluid velocity have been presented and discussed for the related parameters.
\end{abstract}

Keywords: MHD, boundary layer, nonlinear differential equations, and Keller box method

\section{INTRODUCTION}

In 1973, McCormack \& Crane [8] introduced the stretching sheet problem. The stretching problems for steady flow have been used in various engineering and industrial processes, like non-Newtonian fluids, MHD flows, porous plate, porous medium and heat transfer analysis.

Magnetohydrodynamics (MHD) is the study of the interaction of conducting fluids with electromagnetic phenomena. The flow of an electrically conducting fluid in the presence of a magnetic field is important in various areas of technology and engineering such as MHD power generation, MHD flow meters, MHD pumps, etc.

Chiam [7] investigated the MHD flow of a viscous fluid bounded by a stretching surface with power law velocity. He obtained the numerical solution of the boundary value problem by using the Runge-Kutta shooting algorithm with Newton iteration. Hayat et al. [6] applied the modified Adomian decomposition method with the Padé approximation and obtained the series solution of the governing nonlinear problem.

Rashidi in [4] used the differential transform method with the Padé approximant and developed analytical solutions for this problem. In $[1,2]$ applied the HAM in order to obtain an analytical solution of the governing nonlinear differential equations.

In this paper, MHD boundary layer equation is solved with the help of implicit finite difference Keller box method and various results are discussed graphically.

\section{GOVERNING EQUATIONS}

Consider the Magnetohydrodynamic flow of an incompressible viscous fluid over a stretching sheet at $y=0$. The fluid is electrically conducting under the influence of an applied magnetic field $\mathrm{B}(\mathrm{x})$ normal to the stretching sheet. The induced magnetic field is neglected. The resulting boundary layer equations are as follows [6]

$$
\begin{aligned}
& \frac{\partial u}{\partial x}+\frac{\partial v}{\partial y}=0 \\
& u \frac{\partial u}{\partial x}+v \frac{\partial v}{\partial y}=v \frac{\partial^{2} u}{\partial y^{2}}-\sigma \frac{B^{2}(x)}{\rho} u
\end{aligned}
$$

where $\mathrm{u}$ and $\mathrm{v}$ are the velocity components in the $\mathrm{x}$ - and $\mathrm{y}-$ directions respectively, $\boldsymbol{V}$ is the kinematic viscosity, $\rho$ is the fluid density and $\sigma$ is the electrical conductivity of the fluid. In equation (2), the external electric field and the polarization effects are negligible and following Chiam [7] we assume that the magnetic field $\mathrm{B}$ takes the form

$$
B(x)=B_{0} x^{(n-1) / 2}
$$

The boundary conditions corresponding to the non-linear stretching of the sheet are [6]

$$
u(x, 0)=c x^{n}, v(x, 0)=0
$$


$u(x, y) \rightarrow 0, y \rightarrow \infty$ where $\mathrm{c}$ and $\mathrm{n}$ are constants.

using the following substitutions

$$
\begin{gathered}
t=\sqrt{\frac{c(n+1)}{2 v} x^{\frac{n-1}{2}} y} \\
u=c x^{n} f^{\prime}(t) \\
v=-\sqrt{\frac{c(n+1)}{2 v}} x^{\frac{n-1}{2}}\left[f(t)+\frac{n-1}{n+1} t f^{\prime}(t)\right]
\end{gathered}
$$

Equation (1)-(2) are transformed to

$$
f^{\prime \prime \prime}(t)+f(t) f^{\prime \prime}(t)-\beta\left(f^{\prime}(t)\right)^{2}-M f^{\prime}(t)=0
$$

with the following boundary conditions

$f(0)=0, f^{\prime}(0)=1, f^{\prime}(\infty)=0$

Where $\beta=\frac{2 n}{n+1}, M=\frac{2 \sigma B_{0}{ }^{2}}{\rho c(1+n)}$.

\section{KELLER BOX METHOD}

Equation (3) subject to the boundary conditions (4) is solved numerically using implicit finite difference method that is known as Keller-box in combination with the Newton's linearization techniques as described by Cebeci and Bradshaw [3]. This method is unconditionally stable and has secondorder accuracy.

In this method the transformed differential equation (3) are writes in terms of first order system, for that introduce new dependent variable $u, v$ such that

$$
\begin{aligned}
& f^{\prime}=u \\
& u^{\prime}=v
\end{aligned}
$$

Where prime denotes differentiation with $\mathrm{t}$.

$$
v^{\prime}+f v-\beta u^{2}-M u=0
$$

with the new boundary conditions

$$
f(0)=0, u(0)=1, u(\infty)=0
$$

Now, write the finite difference approximations of the ordinary differential equations (5)-(6) for the midpoint $\left(x^{n}, t_{j-\frac{1}{2}}\right)$ of the segment using centered difference derivatives, this is called centering about $\left(x^{n}, t_{j-\frac{1}{2}}\right)$.

$$
\begin{gathered}
\frac{f_{j}^{n}-f_{j-1}^{n}}{h_{j}}=\frac{u_{j}^{n}+u_{j-1}^{n}}{2} \\
\frac{u_{j}^{n}-u_{j-1}^{n}}{h_{j}}=\frac{v_{j}^{n}+v_{j-1}^{n}}{2}
\end{gathered}
$$

Now, ordinary differential equation (7) is approximated by the centering about the mid-point $\left(x^{n-\frac{1}{2}}, t_{j-\frac{1}{2}}\right)$ of the rectangle. In first step we center about $\left(x^{n-\frac{1}{2}, t}\right)$ without specifying t.

$$
\begin{aligned}
& \left(v^{\prime}\right)^{n}+(f v)^{n}-\beta\left(u^{2}\right)^{n}-M u^{n} \\
& \quad=-\left[\left(v^{\prime}\right)^{n-1}+(f v)^{n-1}-\beta\left(u^{2}\right)^{n-1}-M u^{n-1}\right]
\end{aligned}
$$

Now centering about ${ }^{j-\frac{1}{2}}$ (for simplicity, remove n)

$$
\begin{aligned}
& \left(\frac{v_{j}-v_{j-1}}{h_{j}}\right)+\left[\frac{f_{j}+f_{j-1}}{2}\right]\left[\frac{v_{j}+v_{j-1}}{2}\right]- \\
& \beta\left[\frac{u_{j}+u_{j-1}}{2}\right]\left[\frac{u_{j}+u_{j-1}}{2}\right]-M\left[\frac{u_{j}+u_{j-1}}{2}\right]= \\
& -\left[\frac{v_{j}-v_{j-1}}{h_{j}}+(f v)_{j-1 / 2}-\beta\left(u^{2}\right)_{j-1 / 2}-M u_{j-1 / 2}\right]^{n-1}
\end{aligned}
$$

Now linearize the nonlinear system of equations (9)-(11) using the Newton's quasi-linearization method [5] For that use, 


$$
\begin{aligned}
& f_{j}^{n+1}=f_{j}^{n}+\delta f_{j}^{n} \\
& u_{j}^{n+1}=u_{j}{ }^{n}+\delta u_{j}{ }^{n} \\
& v_{j}^{n+1}=v_{j}{ }^{n}+\delta v_{j}{ }^{n}
\end{aligned}
$$

Equation (8) to(10) can be rewritten as

$$
\begin{gathered}
\delta f_{j}-\delta f_{j-1}-\frac{h_{j}}{2}\left(\delta u_{j}+\delta u_{j-1}\right)=\left(r_{1}\right)_{j} \\
\delta u_{j}-\delta u_{j-1}-\frac{h_{j}}{2}\left(\delta v_{j}+\delta v_{j-1}\right)=\left(r_{2}\right)_{j} \\
\left(a_{1}\right)_{j} \delta v_{j}+\left(a_{2}\right)_{j} \delta v_{j-1}+\left(a_{3}\right)_{j} \delta f_{j}+\left(a_{4}\right)_{j} \delta f_{j-1}+ \\
\left(a_{5}\right)_{j} \delta u_{j}+\left(a_{6}\right)_{j} \delta u_{j-1}=\left(r_{3}\right)_{j}
\end{gathered}
$$

The linearized difference system of equations (12)-(14) has a block tridiagonal structure. In a vector matrix form, it can be written as

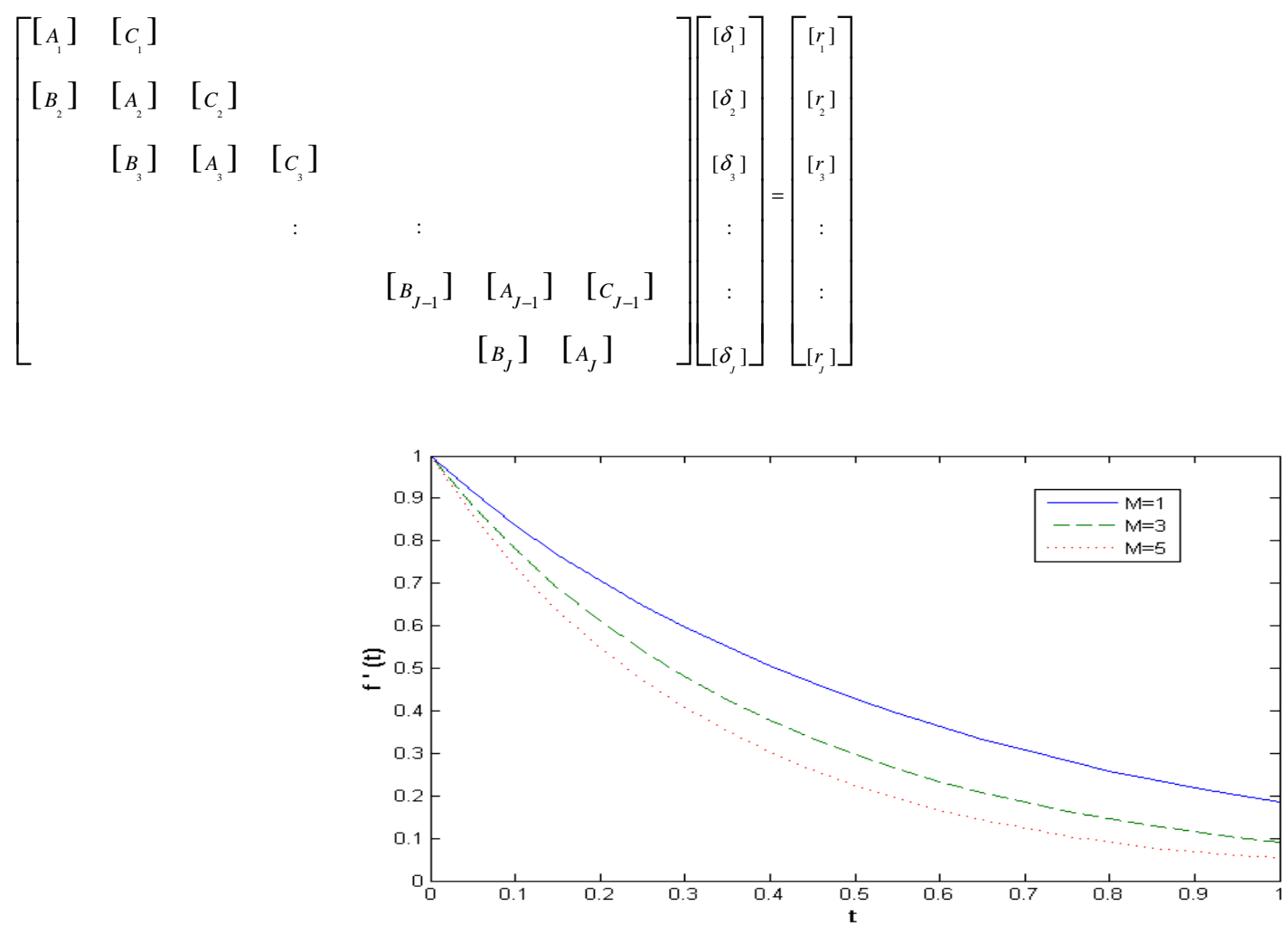

Fig -1:.Effect of Magnetic Parameter on fluid velocity obtained by Keller Box Method for $\beta=1$ 


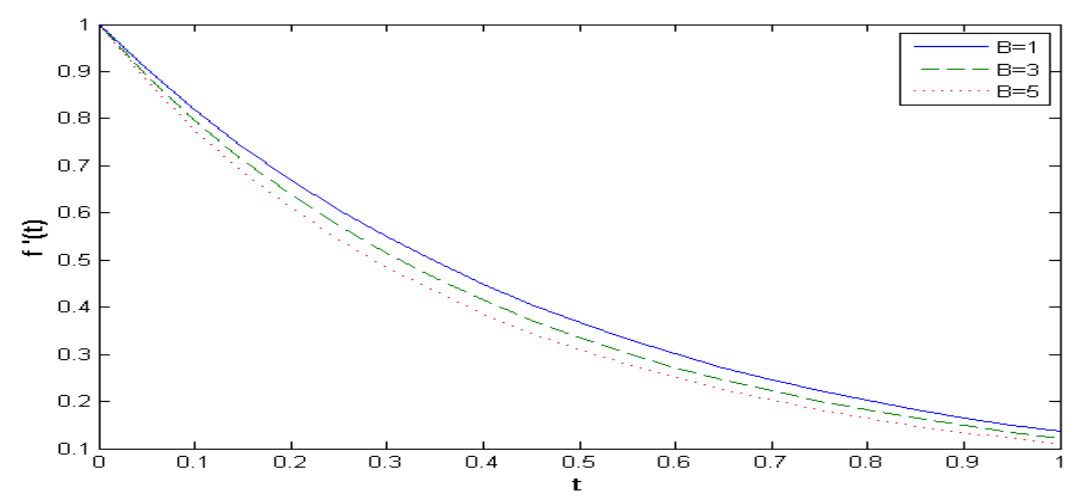

Fig -2: Effect of ${ }^{\beta}$ on fluid velocity obtained by Keller Box Method when $M=2$

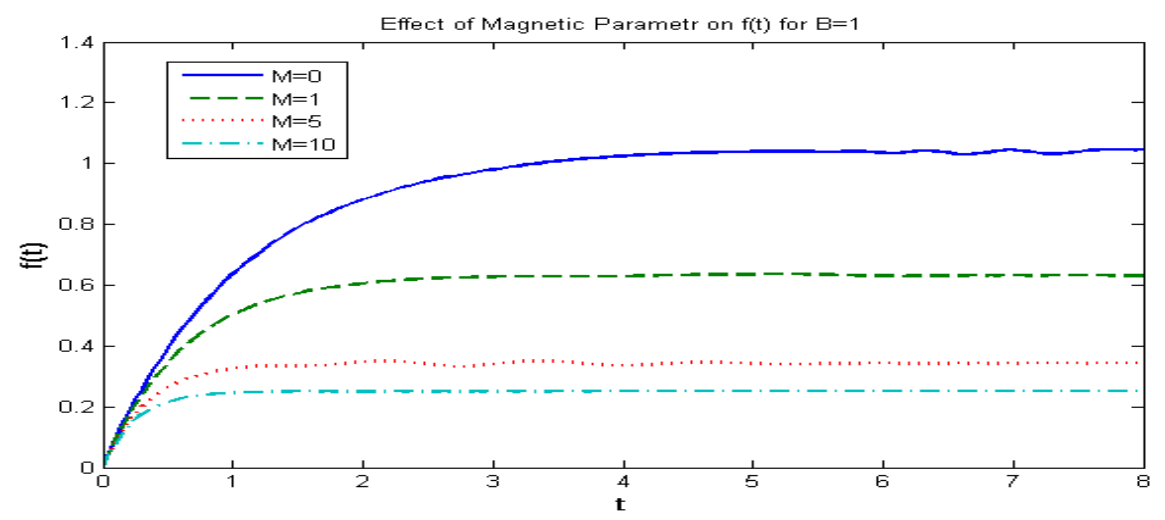

Fig -3: Effect of Magnetic Parameter on $\mathrm{f}(\mathrm{t})$ obtained by Keller Box Method for $\beta=1$

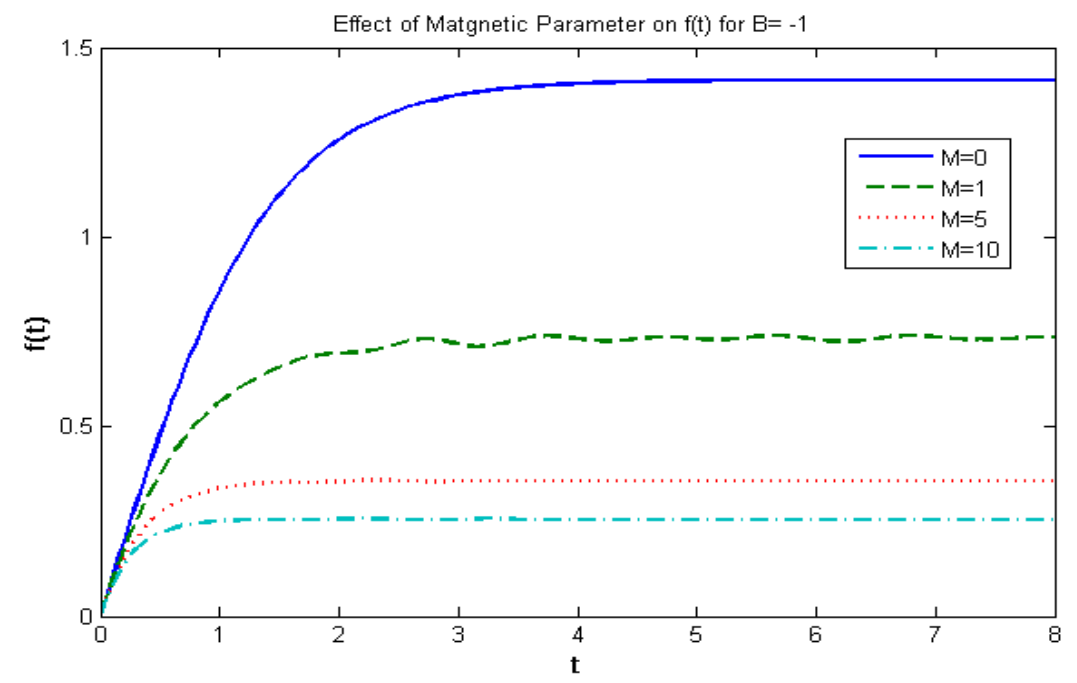

Fig -4: Effect of Magnetic Parameter on $\mathrm{f}(\mathrm{t})$ obtained by Keller Box Method for $\beta=-1$ 


\section{CONCLUSIONS}

In this study, MHD viscous flow over a stretching sheet is considered. Keller Box Method is applied to solve the governing nonlinear differential equation. The results indicate that the velocity will be reduced by increasing the two parameters of $\mathrm{M}$ and $\beta$; however, effect of " $\mathrm{M}$ " in reduction of the velocity components is more than " $\beta$ ". Therefore, it can be concluded that Keller Box is one of the best method to study on MHD viscous flow numerically and get the appropriate results.

\section{REFERENCES}

[1] A.Mehmood, S. Munawar, A. Ali, Comments to: "Homotopy analysis method for solving the MHD flow over a non-linear stretching sheet (Commun. Nonlinear Sci. Numer. Simulat. 14 (2009) 2653-2663)", Communications in Nonlinear Science and Numerical Simulation, 15 (2010) 4233-4240.

[2] A.R. Ghotbi, Homotopy analysis method for solving the MHD flow over a non-linear stretching sheet, Communications in Nonlinear Science and Numerical Simulation,14 (2009) 2653-2663.

[3] Cebeci T., Bradshaw P. Physical and computational Aspects of Convective Heat Transfer, New York: Springer (1988), 391-411.

[4] M.M. Rashidi, The modified differential transform method for solving MHD boundary-layer equations, Computer Physics Communication, 180 (2009), 22102217.

[5] Na T.Y., Computational Methods in Engineering Boundary Value Problem. New York: Academic Press (1979), 111-118.

[6] T. Hayat, Q. Hussain, T. Javed, The modified decomposition method and Padé approximants for the MHD flow over a non-linear stretching sheet, Nonlinear Analysis: Real World Applications, 10 (2009), 966-973.

[7] T.C. Chiam, Hydromagnetic flow over a surface stretching with a power-law velocity, Int. J. Eng. Sci. 33 (1995), 429-435.

[8] McCormack P.D., Crane L., "Physics of Fluid Dynamics", New York, Academic Press, (1973). 